\title{
"The Last Tree", exercising the Computational Thinking through a Graph Grammar based educational game
}

Original Title: "Última Árvore", exercitando o Pensamento Computacional por meio de um jogo educacional baseado em Gramática de Grafos

\section{Braz Araujo da Silva Junior ${ }^{1,2}$, Simone André da Costa Cavalheiro ${ }^{2}$, Luciana Foss ${ }^{2}$}

${ }^{1}$ Mestrado em Computação, Universidade Federal de Pelotas (UFPel) - Pelotas, RS - Brasil

${ }^{2}$ Centro de Desenvolvimento Tecnológico, Universidade Federal de Pelotas (UFPel) - Pelotas, RS - Brasil

\begin{tabular}{l} 
ARTICLE INFO \\
\hline Article history: \\
Received 15 March 2018 \\
Accepted 25 October 2018 \\
Available online July 1st 2018 \\
\hline Keywords: \\
Educational Game \\
Computational Thinking \\
Graph Grammar
\end{tabular}

ISSN: $2595-9077$

DOI: JCThink.2018.v2.n1.p3

\section{ABSTRACT}

INTRODUCTION: This work presents an educational board game based on graph grammars to develop computational thinking skills. Graph grammars are formal languages that generalizes Chomsky's grammars, where strings are replaced by graphs. OBJECTIVE: This game aims to explore the relations between graph grammars and computational thinking skills. It provides an alternative approach to promote computational thinking while introducing formal methods to $K-12$. METHOD: The game was developed under the ENgAGED process, a computer science educational games development methodology that meets design and instructional theories. The process covers analytical, conceptual, construction, application and evaluation phases. RESULTS: Four groups of students were evaluated with graph grammar tests. Two groups of students had positive results, increasing their average performances on the tests by $28 \%$ and $3 \%$. One group kept its performance and the other group was not considered due to its lack of cooperation. CONCLUSION: This work provides "The Last Tree" as product, an instructional tool wherein the students manage a graph grammar while developing computational thinking skills. The game highlights graph grammars features such as: being visual, intuitive and yet formal languages; and high stimulation of data collection and analysis. The application and the tests showed the link between playing performance and general graph analysis and management abilities.

RESUMO

INTRODUÇÃO: Este trabalho apresenta um jogo educacional, de tabuleiro, baseado em gramática de grafos para desenvolver habilidades do pensamento computacional. Gramáticas de grafos são linguagens formais que generalizam as gramáticas de Chomsky, onde strings são substituídas por grafos. OBJETIVO: Este jogo visa explorar as relações entre gramáticas de grafos e habilidades do pensamento computacional. Ele propõe uma abordagem alternativa para promover $o$ pensamento computacional introduzindo métodos formais na educação básica. MÉTODO: O jogo foi desenvolvido sob o processo ENgAGED, uma metodologia de desenvolvimento de jogos educacionais para a computação que reúne teorias instrucionais e de design. $O$ processo abrange fases analíticas, conceituais, de construção, aplicação e avaliação. RESULTADOS: Quatro grupos de estudantes foram avaliados com testes de gramática de grafos. Dois destes grupos obtiveram resultados positivos, aumentando suas médias nos testes em $28 \%$ e 3\%. Um grupo manteve as notas e o outro não foi considerado por não ter cooperado com as atividades. CONCLUSÃO: Este trabalho disponibiliza "A Última Árvore" como produto, uma ferramenta instrucional onde os estudantes manuseiam uma gramática de grafos enquanto desenvolvem habilidades do pensamento computacional. O jogo destaca características das gramáticas de grafos, como: ser uma linguagem visual, intuitiva e ainda assim formal; e alto estímulo à coleta e análise de dados. A aplicação $e$ os testes mostraram a relação entre o desempenho no jogo $e$ as habilidades gerais de análise e manipulação de grafos. 


\section{Introdução}

Jeannette Wing (2006) lista as variadas nuances da ciência da computação, seus processos e habilidades desenvolvidas através dela, nomeando este vasto conjunto de elementos da computação que visam a resolução de problemas, Pensamento Computacional (PC). Todos os estudantes da atualidade irão viver uma vida fortemente influenciada por computação e muitos deles trabalharão em campos envolvidos ou influenciados pela computação. Portanto, não é mais suficiente que se espere até a universidade para iniciar o desenvolvimento do PC. É necessário que estudantes préuniversitários comecem a lidar com a resolução algorítmica de problemas, métodos e ferramentas computacionais (Barr e Stephenson, 2011).

Portanto, o PC ganhou uma visibilidade especial na educação básica (primária e secundária, também conhecida como K-12) e suscitou uma colaboração de profissionais da área da educação, a International Society for Tecnology in Education (ISTE), a Computer Science Teachers Association (CSTA) e a National Science Foundation (NSF). Desta colaboração foram criados materiais para servirem como base para a implementação de cursos de desenvolvimento do PC. Um destes materiais, o Computational Thinking Leadership Toolkit (CSTA, ISTE e NSF, 2009), disponibiliza a definição operacional para o termo PC que é seguida neste trabalho. Entre as habilidades que compõem o PC estão a coleta, análise e representação de dados, abstração, algoritmos e procedimentos. Bombasar et al. (2015) faz um levantamento que aponta que diversos esforços têm sido feitos para desenvolver o PC na educação básica, sendo mais comuns as abordagens que utilizam a linguagem de programação Scratch (Resnick et al, 2009), robótica e computação desplugada (Bell et al, 2009).

Ao observar relações entre linguagens formais e características fundamentais do PC, como a coleta e análise de dados de forma ampla, intuitiva e não-ambígua, propõese a utilização de uma Gramática de Grafos (GG) para desenvolver o PC. As GG são generalizações das gramáticas de Chomsky, o que permite que a modelagem, projeção e solução de problemas sejam realizadas de forma rigorosa e eficaz por meio de métodos matemáticos (Ehrig, 1997). Mas mantendo uma identidade visual, o que fornece uma descrição intuitiva até mesmo para a manipulação de estruturas complexas como as que existem em bancos de dados, sistemas operacionais e softwares mais complexos. Para a implementação de tal proposta, é necessário encontrar abordagens eficientes de ensino. Motivação tem sido considerada um importante passo no aprendizado. Segundo Garris et al. (2002), isto trás os jogos como poderosas ferramentas na educação, pois jogos induzem um estado de fluxo (Nakamura e Csikszentmihalyi, 2009), que aumentam a motivação, o que por sua vez auxilia no aprendizado. No entanto, Battistella e Wangenheim (2016b) apresenta um levantamento de 107 jogos educacionais da área da computação, onde somente 6 explicitam em sua metodologia de desenvolvimento alguma fundamentação teórica quanto ao design instrucional e de jogos.

Portanto, é relevante o desenvolvimento de jogos educacionais com fundamentações teóricas robustas. Este trabalho utiliza o processo ENgAGED (Battistella e Wangenheim, 2016a) para guiar seu desenvolvimento, considerando teorias bem estabelecidas como: ADDIE (Branch, 2009); Taxonomia de Bloom et al. (1956); sua versão revisada (Anderson et al, 2001); e o modelo de avaliação em 4 níveis de Kirkpatrick e Kirkpatrick (2006). O processo tem como produto "A Última Árvore", um jogo educacional baseado em GG para o desenvolvimento do PC. O jogo simula o processo natural de expansão de uma floresta apresentando o ciclo de crescimento das árvores e a disseminação das sementes por agentes externos (os animais).

Os esforços deste artigo têm como objetivo consolidar "A Última Árvore" como uma ferramenta consistente e gradativa de ensino e desenvolvimento do PC, 
aprimorando o jogo através de metodologias bem estabelecidas de desenvolvimento de jogos. Além de estendê-lo a fim de incorporar diferentes níveis de complexidade e novos elementos de GG. Para isto: segue-se a metodologia para desenvolvimento de jogos para o ensino de computação, ENgAGED; apresenta-se definições de GG para a especificação das GG que representam o jogo formalmente; analisa-se os relacionamentos entre GGs e as habilidades do PC; analisa-se os requisitos de aprendizagem através da Taxonomia de Bloom Revisada (Anderson et al, 2001), que discute sobre o processo cognitivo e o conhecimento, organizando-os como duas dimensões que se relacionam; disponibiliza-se o jogo enquanto produto, com todas as suas artes e componentes finalizados e suas versões anteriores; relata-se a experiência de uma aplicação do jogo em sala de aula; e avalia-se o conhecimento dos alunos, antes e depois da aplicação através de pré e pós testes.

Este artigo está organizado como segue. A seção 2 introduz os dois pilares fundamentais deste trabalho, o PC e a GG e discute as relações entre eles. A seção 3 apresenta a abordagem de jogos educacionais e a metodologia seguida para o desenvolvimento do jogo. A seção 4 detalha o fluxo de elaboração do jogo pelos moldes do processo ENgAGED. A seção 5 expõe o jogo e a especificação da GG que o descreve, bem como dados sobre uma aplicação e avaliação. Por fim, a seção 6 conclui $\mathrm{o}$ artigo com as considerações finais.

\section{Pensamento Computacional e Gramática de Grafos}

O Pensamento Computacional (PC) é um termo que começou a circular no meio acadêmico em 2006, com a publicação de um artigo onde Jeanette Wing (2006) analisa um conjunto de habilidades que profissionais da computação desenvolvem para resolver problemas. Por estas habilidades auxiliarem no processo de resolução de problemas, acabam por influenciar quase todas as áreas do conhecimento, das ciências às humanidades (Wing, 2008). Este conceito de PC acendeu um profundo engajamento com questões fundamentais acerca do que é a ciência da computação e no que ela pode contribuir para a resolução de problemas em todo o espectro da investigação humana (Barr e Stephenson, 2011).

Em 2009, para viabilizar a exploração do PC na educação básica, a Computer Science Teachers Association (CSTA) e a International Society for Technology in Education (ISTE) colaboraram para criar materiais de apoio e referência para o desenvolvimento do PC. Um destes materiais, o Computational Thinking Leadership Toolkit (CSTA, ISTE e NSF, 2009), lista algumas habilidades fundamentais do pensamento computacional: Coleta de Dados, o processo de coletar informação apropriadamente; Análise de Dados, atribuição de sentido aos dados, reconhecimento de padrões e extração de conclusões; Representação de Dados, retrato e organização dos dados em grafos, quadros, palavras ou imagens apropriadas; Decomposição de Problemas, quebra de tarefas em partes menores e mais manejáveis; Abstração, redução de complexidade para definir a ideia principal; Algoritmos e Procedimentos, série de passos ordenados seguidos para resolver um problema ou alcançar algum fim; Automação, uso de computadores ou máquinas para realizar tarefas repetitivas ou tediosas; Simulação, representação ou modelo de um processo. Também envolve execução de experimentos utilizando modelos; e Paralelismo, organização de recursos para executar tarefas simultaneamente para alcançar um objetivo em comum.

A Gramática de Grafos (GG) é uma generalização das gramáticas de Chomsky, substituindo strings por grafos (Ehrig, 1997). Ou, pode ainda ser considerada uma generalização de redes de Petri, permitindo mudanças dinâmicas na topologia do sistema e referências entre tokens (Ribeiro, 2000). Assim, uma GG é um formalismo 
que utiliza estruturas gráficas (grafos), e portanto, visual, que simula o comportamento de um sistema através de mudanças de estados onde estas mudanças devem obedecer a regras de transformação de grafos.

O elemento central de uma GG é o grafo, composto por dois conjuntos de elementos chamados de vértices (ou nodos) e arestas, além de mapeamentos de origem e destino destas arestas. Vértices são os elementos atômicos de representação, podendo virtualmente simbolizar qualquer coisa. Enquanto as arestas são elementos compulsoriamente relacionais, que simbolizam vínculos entre os vértices (ainda que de um vértice consigo mesmo). Há ainda outros elementos relacionais, chamados de atributos, que simbolizam relações de um vértice com um valor (podendo ser um inteiro, booleano, etc). As regras das gramáticas de grafos são representadas por dois grafos: o lado esquerdo simbolizando a condição para a aplicação da regra; e o lado direito, simbolizando a consequência. Regras também podem ter grafos adicionais que simbolizam proibições, as condições negativas de aplicação (NACs, do inglês Negative Application Condition). Uma GG é composta por três elementos: um grafo-tipo, que define o universo da gramática, os tipos de vértices e arestas que existem na gramática; um grafo inicial, que define a configuração inicial do sistema; e um conjunto de regras, que definem os comportamentos possíveis do sistema através de regras de transformação de grafos.

Dentre os apontamentos levantados por Bombasar et al. (2015) está o fato de métodos formais serem uma abordagem raramente explorada na educação. Através de métodos matemáticos, os métodos formais estabelecem maneiras de construir e analisar sistemas. Isto permite a descrição de sistemas, verificação e análise de propriedades, correção de implementações, otimização, descrição e verificação do processo de desenvolvimento do sistema e até mesmo para orientar no encontro de soluções mais elegantes, simples e eficientes (Ribeiro, 2000).

A GG trás consigo todos estes benefícios dos métodos formais enquanto mantém-se uma linguagem intuitiva e visual. Particularmente, algumas das características de GG relacionam-se com habilidades fundamentais do PC, tornando-a uma candidata ainda mais conveniente para o preenchimento da lacuna de métodos formais na educação.

- Coleta de Dados: Por ter como elemento central uma estrutura gráfica simples, o grafo, a GG permite uma visualização ampla e completa dos dados. Todo o sistema fica exposto, evidenciando seus componentes e relações. O poder de visualização é tão expressivo que é um passo comum a utilização de estruturas como grafos para auxiliar na organização e visualização de dados, como na construção de estruturas de fluxogramas para representar sistemas e algoritmos.

- Análise de Dados: A GG é especificada formalmente por um modelo matemático, com definições compactadas, precisas e não-ambíguas. Isto garante robustez à sua estrutura, assegurando que o sistema siga um modo de operação bem definido. Isto permite a verificação de propriedades, correção e otimização. A gramática simula o comportamento de sistemas através da alteração de seu estado. Portanto pode-se reconhecer os padrões garantidos estruturalmente e projetar as possíveis alterações no sistema (explorar o espaço de estados).

- Representação de Dados: Intrinsecamente uma linguagem é uma ferramenta para representação. A GG permite organizar dados em estruturas genéricas simples (vértices), que podem manter relacionamentos (arestas). Também estrutura eventos (regras) através de sua bipartição em condição e consequência. Adicionalmente, potencializa a eficiência de representação ao permitir proibições (NACs) e atrelar expressões e operações algébricas (Atributos). É 
capaz de resumir sistemas complexos apresentando-os em apenas três componentes objetivos: grafo-inicial, grafo-tipo e conjunto de regras.

- Decomposição de Problemas: Para que o sistema seja alterado em uma GG é necessário a aplicação de uma regra. Para tal, é necessário o encontro de um match que satisfaça todas as condições da regra. Ao operar a GG, o usuário está em constante contato com a fragmentação das regras em condição e consequência. Também é necessário dividir a tarefa de satisfazer a condição em encontrar matches, verificar se satisfazem a condição positiva, e todas as negativas caso existam.

- Abstração: A substituição de strings por grafos elimina a preocupação com sintaxes textuais, elevando o nível de abstração. Esta é, por exemplo, uma das justificativas para a utilização de linguagens visuais e desenhos no lugar de comandos de texto em cursos introdutórios de programação.

- Algoritmos e Processos: O conjunto de regras está sempre disposto na GG. As regras representam passos atômicos na alteração do sistema. Portanto, pode-se organizar algoritmos projetando-se a aplicação de regras em sequência, tendo-se sempre passos bem definidos em termos de aplicações de regras.

- Automação: Ferramentas para a modelagem, e exploração de estados em uma GG (Rensink, 2003) podem ser utilizadas para a automação de sistemas descritos sobre o formato de GG.

- Simulação: GG é um modelo de alta expressividade, permitindo a simulação de variados sistemas, ainda que complexos. A simulação de um sistema se dá em termos de descrição de seus elementos, suas relações, um estado inicial e a descrição de eventos capazes de alterar seu estado.

- Paralelismo: O caráter descritivo da GG permite trabalhar de maneira natural com conceitos de distribuição, paralelismo e concorrência. A única requisição para a ocorrência de um evento (descrito por uma regra) é o encontro de um match que satisfaça suas condições de aplicação. Portanto, múltiplos eventos podem ocorrer simultaneamente. A GG por si só não limita a simulação a um funcionamento sequencial, ao contrário, por padrão, ela é inteiramente paralela.

O grande destaque da GG é o fato de ser formal e intuitiva ao mesmo tempo, o que também é responsável por trabalhar coleta e análise de dados, como exposto acima. O outro ponto forte é sua expressividade e capacidade para simular sistemas complexos, distribuídos e concorrentes. Características que se relacionam com simulação e paralelismo.

\section{Jogos Educacionais e o método ENgAGED}

Apresentados os relacionamentos da GG com o PC, conclui-se que o formalismo é uma abordagem alternativa justificável para o desenvolvimento do PC. Mas como inseri-lo em um ambiente de ensino-aprendizagem? Jogos possuem um apelo especial em jovens e crianças. Garris et al. (2002) discute que jogos são capazes de despertar um estado de fluxo que aumenta a motivação, que por sua vez é um dos grandes pilares do aprendizado. Este estado de fluxo é um termo da Teoria do Fluxo, ou Flow's Theory, de Nakamura e Csikszentmihalyi (2009). Para que o indivíduo se mantenha neste estado, é necessário um balanceamento entre as oportunidades e capacidades de agir. Isto é, não deve-se exigir muito mais que a capacidade de resposta do indivíduo, mas também não tão pouco a ponto de o indivíduo não sentir-se desafiado. A Figura 1 a seguir ilustra o modelo do estado de Fluxo. 


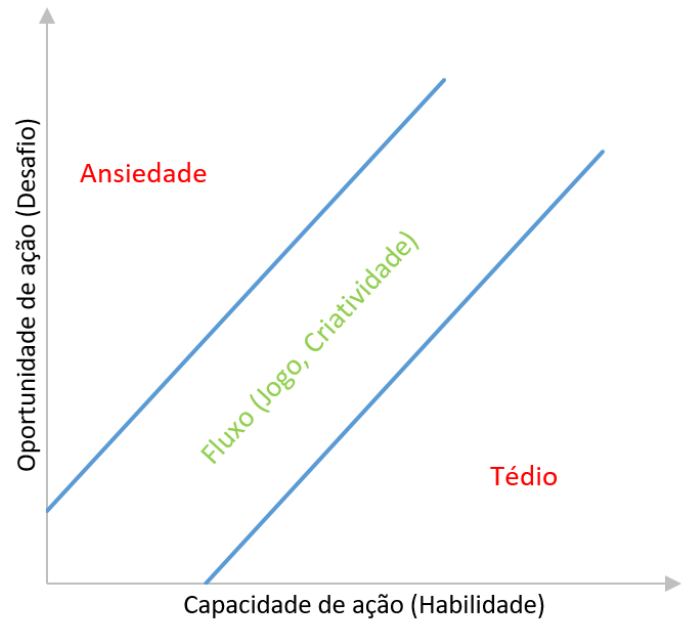

Figura 1. Modelo original de estado de Fluxo, adaptado de Nakamura e Csikszentmihalyi (2009).

A análise feita por Garris et al. (2002) explora ambientes de aprendizado, motivação, a teoria do Fluxo e game design, concluindo que aprendizado e jogo (o processo de jogar) são fundamentalmente construídos sob as mesmas bases. Os jogos educacionais têm aumentado consideravelmente o número de resultados positivos analisados e reportados dentro da comunidade acadêmica, como levantado por Boyle et al. (2016). Desta maneira, elege-se a utilização de um jogo educacional como meio de desenvolvimento do PC através de GG.

No entanto, para assegurar que o jogo alcance seu objetivo enquanto estratégia instrucional, é desejável seguir metodologias bem fundamentadas e comprovadas. Surpreendentemente, a grande maioria dos jogos educacionais na área da computação não apresenta qualquer informação sobre sua metodologia de desenvolvimento, especialmente sobre seus objetivos instrucionais. Isto é evidenciado por Battistella e Wangenheim (2016b), que seleciona 107 jogos educacionais na área da computação para analisar. Destes 107, somente seis expuseram suas metodologias de desenvolvimento. Para auxiliar a diminuir este déficit de fundamentação no desenvolvimento de jogos educacionais na computação, Battistella e Wangenheim (2016a) apresenta o processo ENgAGED (do inglês EducatioNAl GamEs Development). ENgAGED propõe-se a responder a questão: "Como desenvolver jogos educacionais que ensinam competências da Computação de modo efetivo, eficiente e divertido?". Para isto, fundamenta-se em teorias de design instrucional e design de jogos, como:

- ADDIE: do inglês Analyze, Design, Develop, Implement, Evaluate. ADDIE é um processo aplicado para produção de conteúdos que visam aprendizagem baseada em desempenho, dividindo-se em 5 fases: Análise, onde ocorre a identificação do público-alvo e contexto; Projeto, que consiste na definição do conteúdo, o modo e sequenciamento de sua abordagem; Desenvolvimento, produção de todo conteúdo e quaisquer materiais necessários ou auxiliares; Execução, aplicação do conteúdo; e Avaliação, definição de critérios de avaliação e sua condução (Branch, 2009).

- Taxonomia de Bloom: uma maneira de categorizar níveis de raciocínio, são 6 níveis, cada um se referindo a um nível de abstração maior que o anterior: Conhecimento, memorização de materiais previamente aprendidos por fatos, termos, conceitos básicos e respostas; Compreensão, comparação demonstrativa, organizando, comparando, traduzindo e interpretando, fatos e ideias; Aplicação, 
emprego do novo conhecimento, resolução de problemas de novas situações por meio da aplicação de um novo conhecimento, fatos e técnicas; Análise, exame e divisão das informações em partes, identificando causas, fazendo inferência e encontrando provas; Síntese compilação do conjunto de informações de uma maneira distinta; e Avaliação, apresentação de opinião e realização de julgamentos sobre informações e ideias (Bloom et al, 1956).

- Modelo de Avaliação em 4 níveis de Kirkpatrick: um modelo de caracterização de níveis de avaliação de aprendizagem, como segue: Reação, primeiro nivel, avalia como os participantes se sentem sobre a formação ou experiência; Aprendizagem, segundo nível, avalia o aumento do conhecimento ou habilidades (antes e depois); Comportamento, terceiro nível, avalia o grau de um novo aprendizado adquirido durante a aprendizagem, medindo assim o desempenho real em um ambiente de trabalho; e Resultados, quarto nível, avalia o efeito prático da aprendizagem no negócio. Estudos de pós-aprendizagem, observação como parte da formação contínua (Kirkpatrick e Kirkpatrick, 2006).

A Figura 2 ilustra o fluxo que o processo segue, reunindo suas 10 fases: 5 sobre o design instrucional, incluindo análise, projeto, desenvolvimento, execução e avaliação; e 5 sobre o design de jogos, incluindo análise, concepção, design, implementação e teste. A próxima seção descreve o processo de criação do jogo seguindo este fluxo. Uma breve descrição de cada fase é realizada e são apresentados os seus resultados.

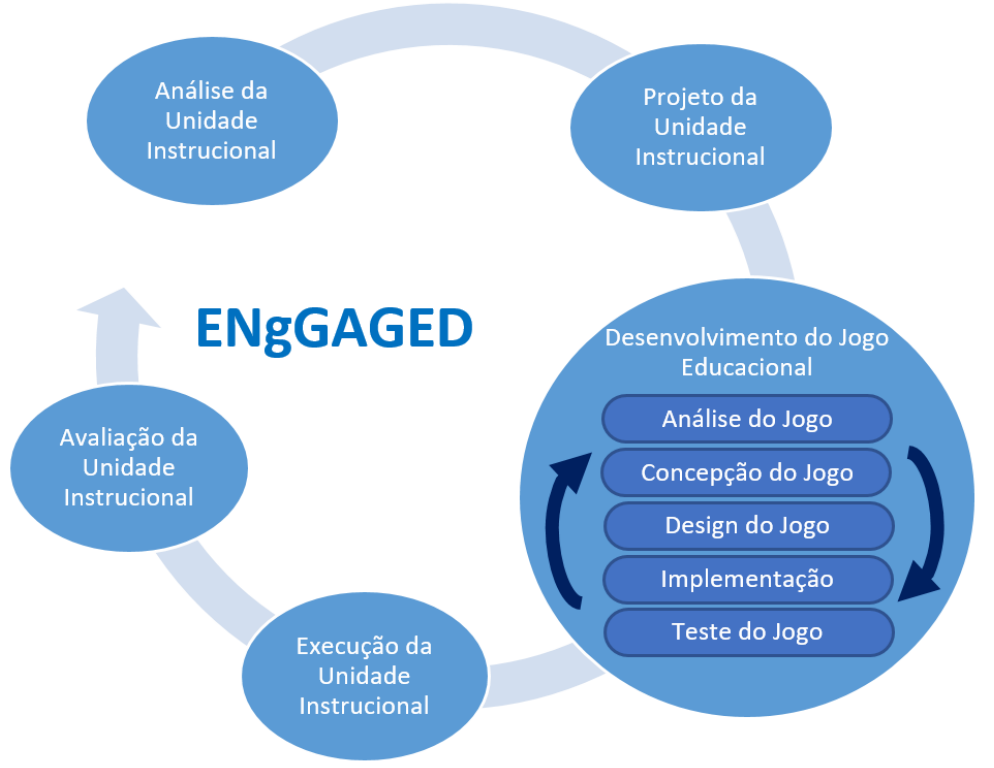

Figura 2. Processo ENgAGED. Adaptado de (Battistella e Wangenheim, 2016a).

\section{Processo de elaboração}

O processo ENgAGED inicia-se com a Análise da Unidade Instrucional (sua Fase 1), que visa definir o escopo da unidade instrucional. Para isto define-se os objetivos a serem alcançados, como discutido, propõe-se como objetivo o desenvolvimento de competências do PC através da introdução de métodos formais (as GGs) na educação básica. $O$ trabalho propõe-se não somente a desenvolver um jogo, mas disponibilizá-lo para que possa ser replicado. Sendo assim, tem-se como público-alvo um público genérico, os alunos do ensino fundamental. Nesta fase também são 
analisados os objetivos de desempenho, isto é, o que espera-se que os alunos desenvolvam e sejam capazes de fazer após a aplicação. Neste trabalho, espera-se que os alunos sejam capazes de:

- Realizar a coleta de dados apresentados no formato de grafos, identificando vértices, arestas e atributos;

- Analisar o estado de um sistema representado por um grafo e suas possíveis alterações dado um conjunto de regras;

- Representar estados e eventos de um sistema no formato de grafos e regras;

- Decompor o processo de aplicação de regra em etapas: encontrar um match, verificar satisfação de cada uma das NACs e derivação do grafo-estado (alvo da regra);

- Elevar o nível de abstração manipulando e compreendendo dados de maneira descritiva e visual;

- Construir algoritmos utilizando sequências de aplicação de regras num dado grafo;

- Simular os comportamentos de um sistema através do modelo de GG; e

- Identificar os fenômenos de paralelismo e concorrência entre regras de uma GG.

A Fase 2, Projeto da Unidade Instrucional, propõe definir as estratégias para se alcançar os objetivos propostos na fase anterior. Com este intuito, opta-se pelo desenvolvimento de um jogo educacional baseado em GG que deve: apresentar todas as informações na categoria de grafos; permitir que os jogadores manipulem uma GG; ter regras que representem de forma clara a ocorrência de eventos no sistema; exigir o encontro de matches, satisfação de NACs e derivações de um grafo-estado; expor dados de maneira descritiva e visual; estimular a construção de algoritmos utilizando sequências de aplicações de regras; representar de forma clara a simulação de um sistema; e conter regras com elementos eventualmente concorrentes. Também nesta fase, define-se a forma de avaliação e acompanhamento do desenvolvimento das habilidades. Como o jogo faz o jogador manipular uma GG, aplicando regras, os movimentos possíveis dos jogadores precisam satisfazer as condições de aplicação das regras. Assim, tentativas de movimentos que não cumpram tais condições devem ser vetadas, seguidas da explicação do veto, durante todo o jogo. É criado um teste de GG. Ele deve ser aplicado antes (pré-teste) e depois (pós-teste) para verificar se houve progresso no aprendizado, nível 2 dos níveis de avaliação de Kirkpatrick e Kirkpatrick (2006).

A fase 3, Desenvolvimento do Jogo Educacional, contém as fases de design do jogo. A primeira delas, fase 3.1, é a análise do jogo, que consiste no levantamento dos requisitos e concepção do jogo. A fim de analisar quais os elementos que o jogo deve ter para ser uma ferramenta instrucional eficiente, considera-se o espectro cognitivo relacionado à dimensão do conhecimento proposto pela Taxonomia de Bloom Revisada (Anderson et al, 2001). A Taxonomia de Bloom et al. (1956) clássica foi apresentada no fim da seção anterior, pois é utilizada no processo ENgAGED, ela divide o processo cognitivo em uma hierarquia de 6 níveis (da base para o topo): conhecimento, compreensão, aplicação, análise, síntese e avaliação. Sua versão revisada, proposta por Anderson et al. (2001), altera esta divisão, removendo síntese e incluindo novos níveis: lembrança, na base da hierarquia, incluindo processos de identificação e reconhecimento, consultas à própria memória; e criação, no topo, se referindo aos processos de produção, planejamento e geração de hipóteses. Além disso, o nível do conhecimento é relacionado a todos os outros e dividido em 4 tipos: factual, de detalhes e elementos específicos; conceitual, de classificações, generalizações e modelos; 
procedural, de técnicas, métodos e algoritmos; e metacognitivo, sobre o próprio processo cognitivo e conhecimento.

Para atingir um aprendizado consistente ao jogar, foram buscadas ações que explorassem cada nuance do processo cognitivo relacionada a cada forma de conhecimento de acordo com a taxonomia revisada. De tal forma que estas ações são, consequentemente, implicações no design do jogo. Estas ações, relativas às relações da taxonomia, estão organizadas no Quadro 1 a seguir.

\begin{tabular}{|c|c|c|c|c|}
\hline & Factual & Conceitual & Procedural & Metacognitivo \\
\hline Lembrar & $\begin{array}{l}\text { Listar } \\
\text { mentalmente as } \\
\text { noções básicas e } \\
\text { intuitivas de } \\
\text { lógica }\end{array}$ & $\begin{array}{l}\text { Reconhecer os } \\
\text { padrões presentes } \\
\text { na definição de } \\
\text { cada ação (regra) }\end{array}$ & $\begin{array}{l}\text { Relembrar como } \\
\text { funcionam } \\
\text { estruturas lógicas, } \\
\text { como condição e } \\
\text { consequência }\end{array}$ & $\begin{array}{l}\text { Identificar, nos } \\
\text { padrões } \\
\text { reconhecidos, } \\
\text { conexões com a } \\
\text { lógica relembrada }\end{array}$ \\
\hline Entender & $\begin{array}{lr}\text { Resumir } & \\
\text { conjuntos } & \text { de } \\
\text { ações } & \text { em } \\
\text { processos } & \text { que } \\
\text { tenham } & \text { como } \\
\text { saída o } & \text { elemento } \\
\text { alvo } & \end{array}$ & $\begin{array}{l}\text { Classificar as } \\
\text { ações que podem } \\
\text { ser tomadas }\end{array}$ & $\begin{array}{l}\text { Elucidar-se } \\
\text { quanto ao impacto } \\
\text { das ações sobre o } \\
\text { objetivo }\end{array}$ & $\begin{array}{lr}\text { Prever } & \text { a } \\
\text { interpretação dos } \\
\text { outros sobre as } \\
\begin{array}{l}\text { suas jogadas e } \\
\text { objetivos }\end{array}\end{array}$ \\
\hline Aplicar & $\begin{array}{lr}\text { Responder às } \\
\text { alterações dos } \\
\text { elementos } \\
\text { correntes no jogo }\end{array}$ & $\begin{array}{l}\text { Fornecer } \\
\text { situações } \\
\text { propícias } \quad \text { ou } \\
\text { restritivas aos } \\
\text { outros jogadores }\end{array}$ & $\begin{array}{lrr}\text { Executar } & \text { uma } \\
\text { ação que } & \text { ajude a } \\
\text { atingir } & \text { o } & \text { seu } \\
\text { objetivo } & & \text { ou } \\
\text { atrapalhe } & \text { o } & \text { dos } \\
\text { outros } & & \\
\end{array}$ & $\begin{array}{l}\text { Usar as ações dos } \\
\text { outros jogadores } \\
\text { para alcançar os } \\
\text { seus objetivos }\end{array}$ \\
\hline Analisar & $\begin{array}{l}\text { Selecionar a } \\
\text { melhor ação dada } \\
\text { a situação } \\
\text { corrente no jogo }\end{array}$ & $\begin{array}{l}\text { Diferenciar as } \\
\text { ações que visam } \\
\text { alcançar objetivo } \\
\text { das que visam } \\
\text { impedir um }\end{array}$ & $\begin{array}{l}\text { Integrar os } \\
\text { elementos } \\
\text { correntes no jogo } \\
\text { aos objetivos e } \\
\text { ações possíveis }\end{array}$ & $\begin{array}{l}\text { Desconstruir } \\
\text { hipóteses dos } \\
\text { outros simulando } \\
\text { tentar alcançar } \\
\text { outro objetivo }\end{array}$ \\
\hline Avaliar & $\begin{array}{lr}\text { Monitorar } & \text { as } \\
\text { ações dos outros } \\
\text { jogadores e seus } \\
\text { progressos }\end{array}$ & $\begin{array}{ll}\text { Determinar as } \\
\text { consequências de } \\
\text { cada ação no } \\
\text { progresso geral }\end{array}$ & $\begin{array}{lr}\text { Julgar } & \text { a } \\
\text { estratégia } & \text { e } \\
\text { objetivo } & \text { dos } \\
\text { outros por } & \text { suas } \\
\text { ações } & \\
\end{array}$ & $\begin{array}{lr}\text { Refletir sobre } & \text { o } \\
\text { progresso } & \text { de } \\
\text { todos e as } \\
\text { distâncias de seus } \\
\text { objetivos }\end{array}$ \\
\hline Criar & $\begin{array}{lr}\text { Gerar, no jogo, } \\
\text { elementos que } \\
\text { façam parte do } \\
\text { seu objetivo }\end{array}$ & $\begin{array}{l}\text { Montar uma } \\
\text { estratégia através } \\
\text { de um conjunto de } \\
\text { ações }\end{array}$ & $\begin{array}{lr}\text { Planejar } & \text { ações } \\
\text { alternativas } & \text { para } \\
\text { se adaptar a } & \text { a } \\
\text { diferentes } & \\
\text { situações } & \end{array}$ & $\begin{array}{lr}\text { Produzir, } & \text { no } \\
\text { jogo, todos } & \text { os } \\
\text { elementos de } & \text { seu } \\
\text { objetivo } & \end{array}$ \\
\hline
\end{tabular}

Quadro 1. Requisitos considerando a Taxonomia de Bloom Revisada.

As ações descritas no Quadro 1 buscam fortalecer o processo de aprendizagem em si, outros requisitos para o design do jogo foram levantados com a finalidade de fortalecer a abordagem do conteúdo. Para isto, foram consideradas as relações entre o PC e a GG abordadas neste trabalho, como discriminadas no Quadro 2 a seguir.

\begin{tabular}{|l|l|l|}
\hline Habilidade do PC & Relação com a GG & Implicações no Design \\
\hline Coleta de Dados & $\begin{array}{l}\text { Ser uma linguagem visual permite a } \\
\text { extração de dados de maneira direta e } \\
\text { ampla, permitindo a visualização do } \\
\text { sistema como um todo. }\end{array}$ & $\begin{array}{l}\text { Todos os elementos do jogo devem ter uma } \\
\text { reprentação gráfica e disponibilizar todos os } \\
\text { dados simultaneamente. }\end{array}$ \\
\hline Análise de Dados & $\begin{array}{l}\text { Uma linguagem formal é composta por } \\
\text { definições precisas e não-ambíguas, o } \\
\text { que permite, entre outras coisas, } \\
\text { verificações de propriedades. }\end{array}$ & $\begin{array}{l}\text { O jomo umteiro deve ser formalmente descrito } \\
\text { precisem ter conhecimento das especificações } \\
\text { formais, devem obedecê-las ao jogar. }\end{array}$ \\
\hline
\end{tabular}




\begin{tabular}{|c|c|c|}
\hline $\begin{array}{l}\text { Representação de } \\
\text { Dados }\end{array}$ & $\begin{array}{l}\text { GGs resumem sistemas em três } \\
\text { componentes com funções bem } \\
\text { definidas: grafo-tipo, conjunto de } \\
\text { regras, e grafo inicial. Eles definem no } \\
\text { sistema, respectivamente, os tipos de } \\
\text { elementos permitidos, como ocorrem as } \\
\text { transições de estado e o estado inicial. }\end{array}$ & $\begin{array}{l}\text { A disposição dos elementos do jogo deve ser } \\
\text { restrita por um grafo-tipo. As ações dos } \\
\text { jogadores devem ser descritas por um conjunto } \\
\text { de regras. E o tabuleiro deve representar um } \\
\text { grafo inicial no início de cada partida. }\end{array}$ \\
\hline $\begin{array}{l}\text { Decomposição de } \\
\text { Problemas }\end{array}$ & $\begin{array}{l}\text { A aplicação de uma regra é subdividida } \\
\text { em três passos: encontrar uma } \\
\text { ocorrência do lado esquerdo da regra; } \\
\text { satisfazer suas NACs; e então } \\
\text { transformar o grafo alvo. }\end{array}$ & $\begin{array}{l}\text { A execução do jogo deve exigir do jogador a } \\
\text { análise de ambos os lados das regras e suas } \\
\text { NACs. Além da habilidade de identificar } \\
\text { matches e transformar grafos apropriadamente, } \\
\text { como a regra aplicada modela. }\end{array}$ \\
\hline Abstração & $\begin{array}{l}\text { Através da substituição dos elementos } \\
\text { textuais por grafos eleva-se o nível de } \\
\text { abstração da sintaxe, tornando-a mais } \\
\text { intuitiva. }\end{array}$ & $\begin{array}{l}\text { O jogador deve encontrar suas ações e } \\
\text { objetivos descritos no formato de grafos, no } \\
\text { lugar de sentenças escritas. }\end{array}$ \\
\hline $\begin{array}{l}\text { Algoritmos } \\
\text { Processos }\end{array}$ & $\begin{array}{l}\text { Regras representam passos atômicos } \\
\text { para a construção de algoritmos bem } \\
\text { definidos. }\end{array}$ & $\begin{array}{l}\text { O jogo deve estimular o sequenciamento de } \\
\text { regras para atingir objetivos intermediários. }\end{array}$ \\
\hline Simulação & $\begin{array}{l}\text { A aplicação de regras a partir do estado } \\
\text { inicial simula os comportamentos } \\
\text { possíveis de um sistema. }\end{array}$ & $\begin{array}{l}\text { O jogo deve representar claramente um sistema } \\
\text { com comportamentos bem definidos e } \\
\text { facilmente reconhecíveis. }\end{array}$ \\
\hline Paralelismo & $\begin{array}{l}\text { O caráter descritivo das GGs define } \\
\text { fenômenos de paralelismo e } \\
\text { concorrência de maneira natural }\end{array}$ & $\begin{array}{l}\text { conjunto de regras deve explorar concorrência, } \\
\text { isto é, incluir pares de regras com elementos } \\
\text { eventualmente concorrentes e pares sem. }\end{array}$ \\
\hline
\end{tabular}

Quadro 2. Design do jogo considerando as relações do PC com GG.

A fase 3.2, concepção do jogo, define os aspectos do jogo em relação ao design de jogos. Estes aspectos e suas justificativas estão dispostos no Quadro 3 a seguir.

\begin{tabular}{|c|c|c|}
\hline Aspecto & Classificação & Justificativa \\
\hline Nome & A Última Ârvore & O nome foi escolhido em virtude da Narrativa. \\
\hline Gênero & Estratégia & $\begin{array}{l}\text { É um gênero que se distancia de ações mecânicas } \\
\text { e tempos de resposta curtos, adequado por focar-se } \\
\text { em processos abstratos e intelectuais que reforçam } \\
\text { o processo de aprendizagem, como as ações } \\
\text { descritas no Quadro } 1 .\end{array}$ \\
\hline Plataforma & Tabuleiro (Não-digital) & $\begin{array}{l}\text { A plataforma de jogo de tabuleiro permite a } \\
\text { disposição de múltiplos dados simultaneamente de } \\
\text { maneira visual e intuitiva. Bem como a } \\
\text { manipulação de peças, podendo representar } \\
\text { elementos do jogo que interagem com os demais } \\
\text { dispostos no tabuleiro. Portanto, converge com as } \\
\text { características desejadas considerando as relações } \\
\text { do PC com a GG, expostas no Quadro } 2 \text {. }\end{array}$ \\
\hline $\begin{array}{ll}\text { Modo } & \text { de } \\
\text { Interação } & \end{array}$ & Multiplayer & $\begin{array}{l}\text { A competição entre jogadores permite que o jogo } \\
\text { tenha um nível de dificuldade dinâmico por ser } \\
\text { parcialmente dependente da habilidade dos } \\
\text { adversários. Portanto, este modo de interação } \\
\text { auxilia na construção de uma ferramenta gradual e } \\
\text { versátil, que possa ser aplicada a jogadores com } \\
\text { diferentes níveis de conhecimento no assunto. } \\
\text { Também ajuda a dinamizar a criação de } \\
\text { estratégias, que devem se adaptar às estratégias } \\
\text { dos adversários. }\end{array}$ \\
\hline Narrativa & $\begin{array}{l}\text { A história do jogo é a de uma } \\
\text { floresta, recém desmatada, onde } \\
\text { restou somente uma árvore. A partir } \\
\text { desta última árvore os animais }\end{array}$ & $\begin{array}{l}\text { Este ambiente foi escolhido por explorar o ciclo } \\
\text { natural de expansão das florestas através de } \\
\text { agentes externos (animais). O ciclo de formação } \\
\text { das árvores: "fruta } \rightarrow \text { semente } \rightarrow \text { planta } \rightarrow \text { árvore }\end{array}$ \\
\hline
\end{tabular}




\begin{tabular}{|c|c|c|}
\hline & $\begin{array}{l}\text { passam a tentar restaurar a floresta, } \\
\text { cada um do seu jeito. }\end{array}$ & $\begin{array}{l}\rightarrow \text { fruta" permite que sejam construídas } \\
\text { sequências (algoritmos) bem definidas para obter } \\
\text { cada um destes elementos. É reforçada a } \\
\text { importância de disseminar as sementes, abrindo } \\
\text { espaço para o estímulo de estratégias de aquisição } \\
\text { e transporte delas. Outro ponto importante é que } \\
\text { ela permite que todos os jogadores, apesar de } \\
\text { terem objetivos individuais, compartilham um } \\
\text { objetivo: restaurar a floresta. Adicionalmente a } \\
\text { narrativa não incentiva a violência e promove a } \\
\text { consciência ambiental. }\end{array}$ \\
\hline Personagens & $\begin{array}{l}\text { O urso; a cobra; o lobo; e o } \\
\text { passarinho. }\end{array}$ & $\begin{array}{l}\text { Os personagens foram criados baseados em } \\
\text { animais da floresta, de forma a garantir a } \\
\text { coerência com a narrativa e reforçar a imersão no } \\
\text { jogo. }\end{array}$ \\
\hline Artefatos & $\begin{array}{l}\text { As frutas; sementes; plantas; e } \\
\text { árvores. }\end{array}$ & $\begin{array}{l}\text { Os artefatos foram criados baseados no } \\
\text { crescimento das plantas, para valer-se da } \\
\text { característica sequencial e cíclica do fenômeno } \\
\text { para o estímulo à produção de algoritmos. }\end{array}$ \\
\hline Cenários & $\begin{array}{l}\text { A floresta, dividida em cinco blocos } \\
\text { de terra. }\end{array}$ & $\begin{array}{l}\text { Os blocos de terra possuem caminhos entre si, } \\
\text { possibilitando andar entre eles. Isto visa reforçar o } \\
\text { papel dos animais como agentes externos que } \\
\text { disseminam as sementes. }\end{array}$ \\
\hline
\end{tabular}

Quadro 3. Aspectos do design do jogo e suas justificativas.

O jogo é modelado como uma GG, as regras (do jogo) definem características externas à GG que o modela. Enquanto as mecânicas, que definem as ações que os jogadores podem tomar, são descritas por regras da GG. Cartas de objetivos individuais são sorteadas para cada jogador no começo da partida. O Quadro 4 a seguir acomoda as regras e mecânicas do jogo, além dos objetivos presentes nestas cartas.

\begin{tabular}{|c|c|c|}
\hline $\begin{array}{l}\text { Aspecto do design } \\
\text { do jogo }\end{array}$ & Nome & Descrição \\
\hline \multirow[t]{5}{*}{ Regras (do Jogo) } & Sorteio dos Objetivos & $\begin{array}{l}\text { Todas as cartas de objetivos devem ser embaralhadas no começo } \\
\text { da partida. Então, cada jogador deve retirar somente uma delas, } \\
\text { sem precisar revelá-la. O restante deve ser mantido virado para } \\
\text { baixo, sem ser revelado. }\end{array}$ \\
\hline & Ordem dos Jogadores & $\begin{array}{l}\text { Os jogadores devem assumir posições diante do tabuleiro e } \\
\text { permanecer nelas até o término da partida. As posições indicarão } \\
\text { de quem é o próximo turno, seguindo sempre a mesma ordem, } \\
\text { em um sentido pré-definido e acordado entre os jogadores. }\end{array}$ \\
\hline & Abertura da Partida & $\begin{array}{l}\text { Para a partida começar, o tabuleiro deve conter exatamente os } \\
\text { elementos descritos no centro do tabuleiro (grafo inicial), como } \\
\text { ilustrado na Figura } 5 \text {. }\end{array}$ \\
\hline & Turnos & $\begin{array}{l}\text { Em seu turno, cada jogador deve realizar uma ação (aplicação de } \\
\text { uma das regras da GG), nem mais nem menos. }\end{array}$ \\
\hline & Vitória & $\begin{array}{l}\text { Quando o tabuleiro estiver com a configuração descrita na carta } \\
\text { de objetivo de um jogador, ele vence da partida. }\end{array}$ \\
\hline \multirow[t]{5}{*}{$\begin{array}{l}\text { Mecânicas } \\
\text { (Regras da GG) }\end{array}$} & Mover & $\begin{array}{l}\text { Um animal pode ser movido de um bloco de terra para outro, } \\
\text { desde que haja um caminho entre eles. }\end{array}$ \\
\hline & Colher & $\begin{array}{l}\text { Um animal pode adquirir uma fruta, desde que esteja sobre um } \\
\text { bloco de terra com ao menos uma árvore. }\end{array}$ \\
\hline & Plantar & $\begin{array}{l}\text { Um animal pode gastar uma fruta para deixar sua semente no } \\
\text { bloco de terra que estiver. }\end{array}$ \\
\hline & Regar & $\begin{array}{l}\text { Um animal pode transformar uma semente do bloco de terra que } \\
\text { estiver em uma planta. }\end{array}$ \\
\hline & Adubar & $\begin{array}{l}\text { Um animal pode gastar uma fruta para transformar uma planta } \\
\text { do bloco de terra que estiver em uma árvore. }\end{array}$ \\
\hline
\end{tabular}




\begin{tabular}{|c|c|c|}
\hline & Comer & Um animal pode consumir duas frutas, removendo-as do jogo. \\
\hline \multirow[t]{12}{*}{ Objetivos } & Ecossistema & $\begin{array}{l}\text { Um animal com uma fruta, sobre um bloco de terra com uma } \\
\text { semente, uma planta e uma árvore. }\end{array}$ \\
\hline & Pomar & Um animal com 3 frutas, sobre um bloco de terra com 3 árvores. \\
\hline & Bosque & Dois blocos de terra com 2 árvores cada e caminhos entre si. \\
\hline & Plantação & Dois blocos de terra com 3 plantas cada e caminhos entre si. \\
\hline & Disseminação & Dois blocos de terra com 3 sementes cada e caminhos entre si. \\
\hline & Alpiste & Um bloco de terra com 5 sementes. \\
\hline & Flora & Um bloco de terra com 5 plantas. \\
\hline & Casa na Árvore & Um bloco de terra com 5 árvores. \\
\hline & Rei das Frutas & Um animal com 5 frutas. \\
\hline & Só Sementes & Um bloco de terra com 3 sementes e 0 plantas. \\
\hline & Expansão Florestal & $\begin{array}{l}\text { Um animal com } 2 \text { frutas sobre um bloco de terra com } 2 \\
\text { sementes, } 0 \text { plantas e } 0 \text { árvores. }\end{array}$ \\
\hline & O Novo e o Velho & $\begin{array}{l}\text { Um animal com } 0 \text { frutas sobre um bloco de terra com } 2 \\
\text { sementes, } 0 \text { plantas e } 2 \text { árvores. }\end{array}$ \\
\hline
\end{tabular}

Quadro 4. Regras e mecânicas do jogo.

A fase 3.3, design do jogo, é definida pela produção das ilustrações e imagens dos elementos do jogo. Todos os elementos são autorais, produzidos ao longo deste trabalho. Personagens diferentes foram criados para reforçar a imersão no jogo, mas para a GG, eles são todos vértices do mesmo tipo, animal. Nesta fase também é definida a modelagem do jogo. Por ser representado por uma GG, esta modelagem é realizada através da ferramenta GRaphs for Object-Oriented VErification (GROOVE) (Rensink, 2003), viabilizando a especificação e simulação da GG do jogo. Na ferramenta é possível simular a execução do jogo, explorando automaticamente todas as possibilidades de aplicação de regras, e registrando todos os passos de derivação utilizados para se alcançar os diferentes estados finais.

A fase 3.4, implementação do jogo, é definida pela preparação de todos os elementos necessários para sua aplicação. No caso de um jogo de tabuleiro, impressão e montagem de seus componentes: cartas de vértices; cartas de números (valores dos atributos); cartas de objetivo; e tabuleiro. Diferentes versões intermediárias foram criadas e disponibilizadas ao longo do trabalho ${ }^{1}$. A versão atual ${ }^{2}$ é composta por: 52 cartas de número (1 a 9) para contagem dos atributos; 4 cartas de personagem (lobo, urso, cobra e passarinho); 12 cartas de objetivo descritos como grafos; e 1 tabuleiro composto por uma matriz $3 \times 3$ de folhas A4.

A Fase 3.5, teste do jogo, é definida pela aplicação do jogo entre seus criadores ou especialistas (conhecedores do conteúdo que ele se propõe a ensinar). A finalidade desta etapa é testar as funcionalidades do jogo, detectar erros e obter feedbacks para melhoria do jogo antes de sua execução (Fase 4). Os testes foram realizados com protótipos de versões iniciais do jogo, como o exibido na Figura 3. A partir dos testes uma série de modificações no jogo foram realizadas, entre elas destacam-se: reorganização do formato das regras, a fim de torná-las mais claras, intuitivas e próximas ao formato de representação usual das GG; união das setas que representam a arestas estarSobre com a carta dos respectivos personagens; e substituição das descrições textuais das cartas de objetivos por grafos.

A fase 4, execução da unidade instrucional, é definida pela aplicação ao públicoalvo. Uma aplicação com alunos do sexto ano de uma escola municipal de Pelotas foi realizada para testar a viabilidade de aplicação do jogo em sala de aula. Esta aplicação é detalhada e discutida no próximo capítulo. A fase 5, avaliação da unidade instrucional, é

\footnotetext{
${ }^{1}$ Para o download das antigas versões do jogo acesse https://goo.gl/oleq4J.

${ }^{2}$ Para o download da versão atual do jogo acesse https://goo.gl/KXvHxH.
} 
definida por uma análise sobre a(s) aplicação(ões) feita(s) na fase anterior. Esta análise usualmente é complementada através de questionários de satisfação (Avaliação de reação, nível 1), pré e pós-testes (Avaliação de aprendizado, nível 2). Uma análise sobre a aplicação também é detalhada no próximo capítulo.

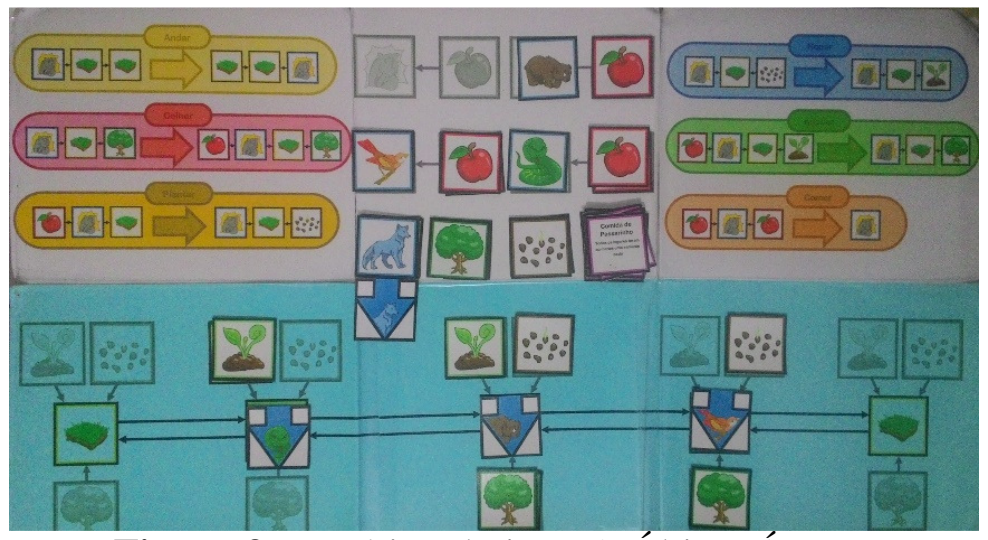

Figura 3. Protótipo do jogo A Última Árvore

Um resumo de todo o processo e suas fases é exibido no Quadro 5 a seguir.

\begin{tabular}{|c|c|}
\hline \multicolumn{2}{|r|}{ Fase 1. Análise da Unidade Instrucional (UI) } \\
\hline $\begin{array}{l}\text { A1.1 Especificar } \\
\text { UI do jogo }\end{array}$ & $\begin{array}{l}\text { Objetivo: desenvolvimento de competências do PC, em particular, coleta e análise de } \\
\text { dados. Além da capacidade de operar GGs. }\end{array}$ \\
\hline $\begin{array}{l}\text { A1.2 } \\
\text { Caracterizar } \\
\text { aprendizes }\end{array}$ & Público-alvo: alunos do ensino fundamental. \\
\hline $\begin{array}{l}\text { A1.3 Definir } \\
\text { objetivo(s) de } \\
\text { desempenho }\end{array}$ & $\begin{array}{l}\text { Os alunos devem ser capazes de: realizar a coleta, análise e manipulação de dados; } \\
\text { decompor e abstrair problemas; traçar algoritmos; e simular eventos. Também devem } \\
\text { estar aptos a: identificar elementos (vértices) e suas relações (arestas) num grafo; } \\
\text { analisar as condições de aplicações de regras de uma GG; aplicar regras } \\
\text { corretamente; perceber concorrência ou paralelismo entre regras; e projetar as } \\
\text { modificações que cada aplicação desencadeia no sistema. }\end{array}$ \\
\hline \multicolumn{2}{|r|}{ Fase 2. Projeto da Unidade Instrucional (UI) } \\
\hline $\begin{array}{l}\text { A2.1 Definir } \\
\text { avaliação do } \\
\text { aluno }\end{array}$ & $\begin{array}{l}\text { As avaliações devem ser realizadas ao final de cada partida. Observa-se a distância } \\
\text { entre a condição do objetivo recebido por cada aluno e o estado final do jogo. } \\
\text { Discutem-se as estratégias tomadas e justificativas para tomá-las, dadas pelos alunos. }\end{array}$ \\
\hline $\begin{array}{l}\text { A2.2 Definir } \\
\text { conteúdo da } \\
\text { estratégia } \\
\text { instrucional }\end{array}$ & $\begin{array}{l}\text { A estratégia instrucional é um jogo educacional baseado em GG para desenvolver o } \\
\text { PC. Nele, deve ser manipulada uma GG, realizando aplicações de regras para } \\
\text { alcançar um objetivo. }\end{array}$ \\
\hline $\begin{array}{l}\text { A2.3 Decidir } \\
\text { pelo } \\
\text { desenvolvimento } \\
\text { ou utilização }\end{array}$ & $\begin{array}{l}\text { Optou-se pelo desenvolvimento já que não se conhece uma proposta similar de jogo } \\
\text { que possa ser utilizada. }\end{array}$ \\
\hline $\begin{array}{lr}\text { A2.4 Revisar } & \text { o } \\
\text { modelo } & \text { de } \\
\text { avaliação } & \text { do } \\
\text { jogo } & \\
\end{array}$ & $\begin{array}{l}\text { Para avaliar o desempenho dos alunos e eficiência do projeto, adotou-se o modelo de } \\
\text { pré e pós testes para a avaliação de aprendizado, diferença do conhecimento antes e } \\
\text { depois, nível } 2 \text { no modelo de avaliação em } 4 \text { níveis de Kirkpatrick e Kirkpatrick } \\
(2006) \text {. }\end{array}$ \\
\hline \multicolumn{2}{|r|}{ Fase 3. Desenvolvimento do Jogo Educacional } \\
\hline $\begin{array}{l}\text { Fase } 3.1 \text { Análise } \\
\text { do Jogo - } \\
\text { Requisitos }\end{array}$ & $\begin{array}{l}\text { Requisitos de aprendizagem descritos no Quadro } 1 . \text { Requisitos para o } \\
\text { desenvolvimento do PC detalhados no Quadro 2. }\end{array}$ \\
\hline $\begin{array}{lr}\text { Fase } & 3.2 \\
\text { Concepção } & \text { do } \\
\text { Jogo }\end{array}$ & $\begin{array}{l}\text { A Última Árvore é uma representação lúdica de uma GG. Nele os jogadores } \\
\text { interpretam animais de uma floresta recém desmatada onde há uma única árvore } \\
\text { restante. Os objetivos de cada jogador são sorteados no início de cada partida. } \\
\text { Somente o próprio jogador tem conhecimento de seu objetivo. Mas todos eles }\end{array}$ \\
\hline
\end{tabular}




\begin{tabular}{|c|c|}
\hline & $\begin{array}{l}\text { norteiam a restauração da floresta, por exemplo: "Um lugar deve possuir } 5 \text { plantas ao } \\
\text { mesmo tempo". Para alcançar os objetivos, os jogadores simulam o processo natural } \\
\text { de expansão de uma floresta, como o ciclo de crescimento das árvores e a } \\
\text { disseminação das sementes por agentes externos (os animais). Em seu turno, cada } \\
\text { jogador realiza uma ação: mover, colher, plantar, regar, adubar ou comer. Vence } \\
\text { quem alcançar primeiro o objetivo sorteado. Mecânicas, regras e objetivos detalhados } \\
\text { no Quadro 4. }\end{array}$ \\
\hline \multicolumn{2}{|r|}{ Fase 3.3. Design do Jogo } \\
\hline $\begin{array}{l}\text { A3.3.1 Definir } \\
\text { engine }\end{array}$ & $\begin{array}{l}\text { Apesar de não se aplicar aos jogos não-digitais, como "A Última Árvore" deve } \\
\text { corresponder a especificação de uma GG, nesta fase foram especificadas as GGs das } \\
\text { diferentes versões do jogo. A GG da versão atual é exibida na Figura } 6 \text {. }\end{array}$ \\
\hline $\begin{array}{lr}\text { A3.3.2 } & \text { Produzir } \\
\text { ilustrações } & \text { ou } \\
\text { imagens } & \text { dos } \\
\text { elementos } & \text { do } \\
\text { jogo } & \end{array}$ & $\begin{array}{l}\text { Nesta fase foram geradas as artes dos produtos. A unidade de "A Última Árvore" é } \\
\text { composta por: um tabuleiro composto por nove folhas A4; } 4 \text { cartas de personagem; } \\
12 \text { cartas de objetivo; e um conjunto de cartas de numerais. Todo o material foi } \\
\text { produzido de forma a facilitar sua implementação, sendo projetados para serem } \\
\text { impressos em folhas A4, exigindo somente alguns recortes nos lugares indicados. } \\
\text { Disponibilizados para download em acesse https://goo.gl/KXvHxH. }\end{array}$ \\
\hline $\begin{array}{l}\text { A3.3.3 Modelar } \\
\text { o jogo }\end{array}$ & $\begin{array}{l}\text { Modelagem feita de forma automatizada. Por ser uma GG, foi utilizada a ferramenta } \\
\text { GROOVE, viabilizando a especificação e simulação da GG definida. Foi possível } \\
\text { simular a execução do jogo, explorando automaticamente todas as possibilidades de } \\
\text { aplicação de regras, e registrando todos os passos de derivação utilizados para se } \\
\text { alcançar os diferentes estados finais. }\end{array}$ \\
\hline $\begin{array}{l}\text { Fase } 3.4 \\
\text { Implementação } \\
\text { do Jogo }\end{array}$ & $\begin{array}{l}\text { Impressão e montagem dos elementos. A Figura } 3 \text { exibe protótipo do jogo, impresso } \\
\text { para testes. A Figura } 5 \text { exibe o tabuleiro da versão atual do jogo. }\end{array}$ \\
\hline $\begin{array}{l}\text { Fase } 3.5 \text { Testes } \\
\text { do jogo }\end{array}$ & $\begin{array}{l}\text { Testes foram realizados com os criadores do jogo e "especialistas", usuários com } \\
\text { conhecimento prévio acerca de linguagens formais: alunos de graduação em } \\
\text { engenharia da computação e ciência da computação. }\end{array}$ \\
\hline \multicolumn{2}{|r|}{ Fase 4. Execução da Unidade Instrucional (Não-Digital) } \\
\hline $\begin{array}{l}\text { A4.1 Planejar a } \\
\text { execução do } \\
\text { jogo }\end{array}$ & $\begin{array}{l}\text { Foram marcadas duas aulas com uma turma do sexto ano da escola municipal } \\
\text { Ferreira Viana para a aplicação do jogo. Assim como impressos testes para aplicação } \\
\text { antes (pré) e depois (pós) da execução. Os testes estão disponíveis em } \\
\text { https://goo.gl/CN3oAV. }\end{array}$ \\
\hline $\begin{array}{l}\text { A4.2 Instalar o } \\
\text { jogo digital }\end{array}$ & Não se aplica. \\
\hline $\begin{array}{l}\text { A4.3 Executar o } \\
\text { jogo }\end{array}$ & $\begin{array}{l}\text { Ao aplicar o jogo, a sala foi dividida em grupos com } 4 \text { alunos cada: o grupo verde, } \\
\text { que obteve ótimo desempenho; o grupo amarelo, que apesar de demonstrar } \\
\text { dificuldades conseguiu completar o jogo e melhorar nos testes; o grupo azul, que não } \\
\text { apresentou diferença alguma entre os testes; e o grupo vermelho, que não } \\
\text { participaram satisfatoriamente das atividades. }\end{array}$ \\
\hline \multicolumn{2}{|r|}{ Fase 5. A valiação da Unidade Instrucional (UI) } \\
\hline $\begin{array}{l}\text { A5.1 Conduzir } \\
\text { avaliação }\end{array}$ & $\begin{array}{l}\text { O pré-teste foi realizado na primeira aula, com a sala inteira. E os pós-testes foram } \\
\text { feitos em grupos, imediatamente após a aplicação do jogo em cada grupo. }\end{array}$ \\
\hline $\begin{array}{lr}\text { A5.2 } & \text { Analisar } \\
\text { dados } & \text { da } \\
\text { avaliação } & \\
\end{array}$ & $\begin{array}{l}\text { Os resultados do pré-teste (Tabela 1) e pós-teste (Tabela 2) foram comparados, } \\
\text { analisando o desempenho individual e de cada grupo, disposto na Tabela } 3 .\end{array}$ \\
\hline
\end{tabular}

Quadro 5. Visão geral do processo de elaboração através do modelo ENgAGED.

\section{O jogo}

Em "A Última Árvore", os alunos interpretam animais em uma floresta recém destruída onde resta somente uma árvore. A partir dela, os jogadores tentam restaurar a floresta, cada um da sua maneira. Para isto, percorrem o ciclo de crescimento das plantas, substituindo elementos no jogo através da aplicação de regras de uma GG (as mecânicas descritas no Quadro 4). 


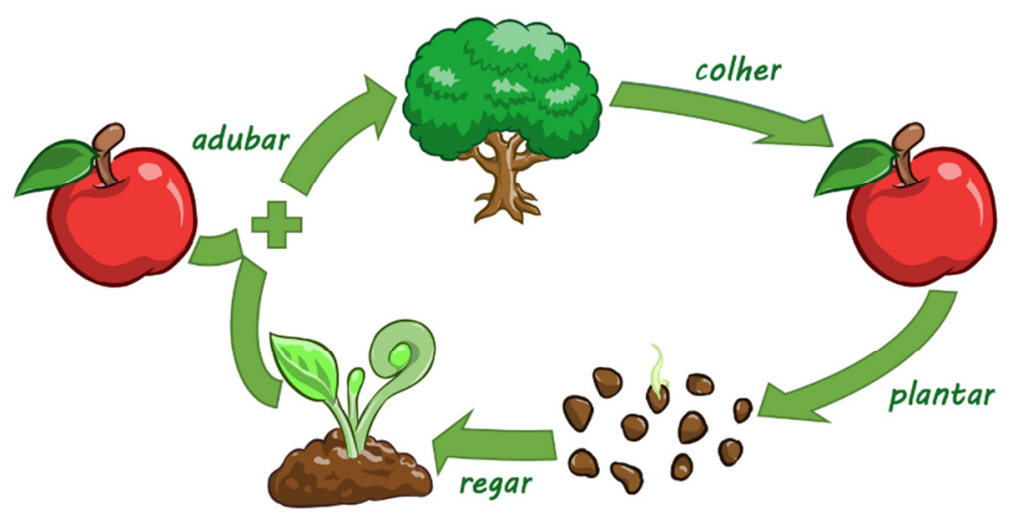

Figura 4. Ciclo de crescimento das plantas adotado para a especificação das regras.

No início do jogo, cada jogador sorteia uma carta de objetivo (descritos no Quadro 4), que descreve a maneira como ele deve deixar a floresta restaurada. Estas cartas indicam as condições de vitória para os jogadores que as sortearem. Isto é, se em algum momento do jogo existir a configuração descrita na carta, o jogador ganha a partida. Qualquer jogador, incluindo os adversários, pode ser responsável por criar a condição de vitória. Com os objetivos em mãos, os jogadores arrumam o tabuleiro respeitando as ilustrações em seu tronco de árvore (grafo inicial da GG). No tabuleiro (Figura 5), o jogador irá encontrar (no topo) um contador de frutas para cada animal, onde os espaços marcados com zeros indicam onde as cartas de número devem ser colocadas para alterar o número de frutas que o animal tem em um dado momento. Da mesma forma, em baixo, cada bloco de terra possui três contadores: de sementes; de plantas; e de árvores. As cartas de personagem devem ser postas sobre os blocos de terra. A Figura 5 exibe o tabuleiro e as cartas que devem estar dispostas sobre ele no início de uma partida. $\mathrm{O}$ tronco da árvore descreve que todos os animais devem estar no bloco de terra central, o qual também deve possuir uma árvore. Para obedecer essa especificação, coloca-se as cartas dos animais (que já possuem as arestas com origem neles) sobre o bloco de terra no tabuleiro, e uma carta de número 1 sobre a marcação correspondente às árvores daquele bloco de terra.

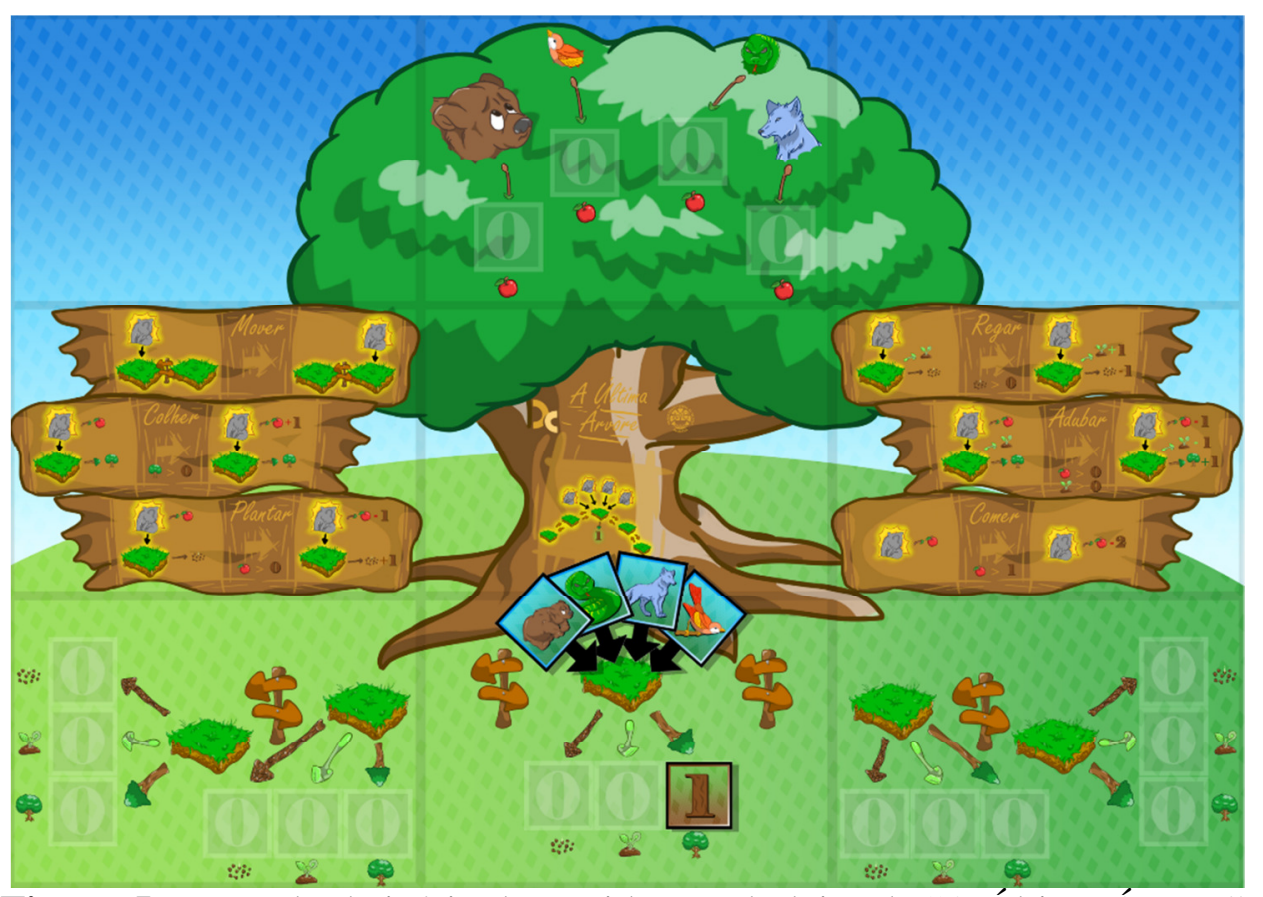

Figura 5. Exemplo de início de partida no tabuleiro de "A Última Árvore". 
Durante a partida, cada jogador realiza uma ação (aplicação de uma das regras da GG) e passa sua vez. Dos dois lados do tronco da árvore no tabuleiro (Figura 5) estão descritas as ações (mecânicas descritas no Quadro 4) que os jogadores podem tomar. A GG que descreve esta versão do jogo é uma AGG com NACs, versões anteriores, com suas respectivas GGs são apresentadas em por Silva et al. (2017a;2017b). Para simplificar o primeiro contato com o jogo, todo o conteúdo adicionado na versão anterior (Silva et al, 2017b) foi desconsiderado: vértices de caçador, turistas, namorados e cidade; arestas com origem ou destino nestes vértices; regras de movimentação destes vértices; e todas as NACs. Mas elas estão presentes na especificação formal, ilustrada na Figura 6, que define o grafo-tipo $\mathrm{T}$, o grafo inicial $\mathrm{G}_{0}$, e as 6 regras básicas (mecânicas do Quadro 4).

Na representação gráfica, cada tipo de vértice tem sua própria ilustração. Arestas também possuem ilustrações diferentes, mas todas em formato de seta. Atributos são representados da mesma maneira, mas com setas vazadas. Grafos são indicados por caixas de contenção com todos os seus elementos em seu interior. Particularmente, grafos de NACs são representados por caixas de contenção vazadas. Os valores de atributos em regras são representados por variáveis, que são definidas por um conjunto de equações ou inequações demonstradas logo abaixo da seta central da regra, entre o lado esquerdo e o lado direito. Variáveis não definidas explicitamente pelas equações podem assumir qualquer valor, por exemplo, na regra Colher tem-se que: um animal com um número $\mathrm{f}$ qualquer de frutas, que esteja sobre um bloco de terra com um número a $>0$ de árvores pode aplicar a regra para passar a ter um número $g=f+1 \mathrm{de}$ frutas, continuando no mesmo bloco de terra, com o mesmo número de árvores. Ou seja, ele pode ganhar uma fruta se estiver em um lugar com árvores. E a NAC desta regra proíbe isto acontecer caso também haja um casal de namorados no mesmo bloco.

Para testar a viabilidade da utilização da ferramenta em sala de aula, aplicou-se o jogo a uma turma do sexto ano de uma escola municipal de Pelotas, E.M. Ferreira Viana. Para a aplicação, foram preparados testes para medir o conhecimento dos alunos acerca de GGs. Eles cumprem a função de pré e pós testes, medindo a diferença do conhecimento antes e depois da aplicação, forma usual de avaliação de aprendizado, nível 2 de Kirkpatrick e Kirkpatrick (2006). A aplicação do jogo foi dividida em dois dias. No primeiro, foi realizada uma breve introdução às GGs e aplicação do pré-teste na sala inteira. No segundo, os alunos foram chamados em grupos de quatro jogadores. Cada grupo era apresentado ao jogo, jogava uma partida e então realizava o pós-teste. Dois dos alunos que participaram do pré-teste faltaram à aula seguinte e, portanto, não foram avaliados. Alguns alunos, depois de jogarem e realizarem o pós-teste, foram convidados a jogar novamente em outro grupo, para que fosse completada a quantidade de quatro jogadores.

Os testes ${ }^{3}$ foram criados com perguntas direcionadas para avaliar competências específicas das GG: Match, sobre a competência de identificar matches corretamente; Aplicação, a habilidade de identificar o grafo resultante após a aplicação de uma regra em um dado grafo-estado; e Atributos, a respeito da capacidade de identificar e manipular atributos. As questões abordam as competências como segue: (1) Match; (2) Aplicação; (3) Match; (4) Aplicação; (5) Atributos; (6) Match e Atributos; (7) Aplicação e Atributos; e (8) Match e Atributos. As tabelas a seguir detalham o resultado dos testes, onde as colunas indicam as questões e/ou nota final. As respostas para cada pergunta foram divididas em: C, reposta certa; E, resposta errada, mas próxima da correta; e X, resposta errada e desconexa com a questão, ou ausência de resposta.

\footnotetext{
${ }^{3}$ Para o download dos testes de gramática de grafos, acesse https://goo.gl/CN3oAV.
} 

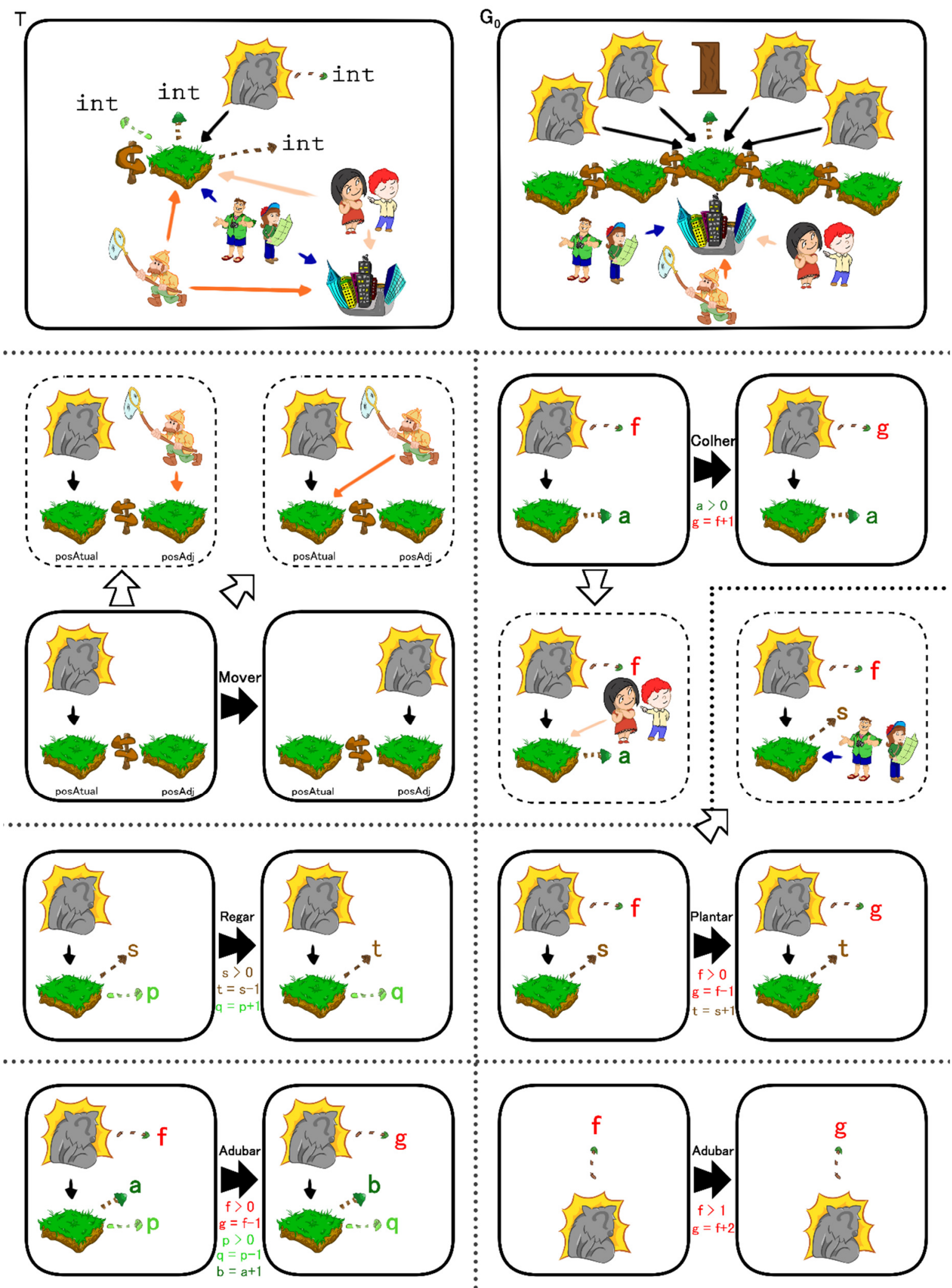

Figura 6. Gramática de Grafos do jogo. 


\begin{tabular}{ccccccccccc}
\hline Aluno & Idade & $(1)$ & $(2)$ & $(3)$ & $(4)$ & $(5)$ & $(5)$ & $(7)$ & $(8)$ & Acertos \\
\hline A & 12 & C & E & C & E & X & C & E & E & 3 \\
B & 15 & C & C & C & E & C & E & C & C & 6 \\
C & 11 & C & C & C & C & C & C & C & C & 8 \\
D & 11 & X & C & C & E & C & E & C & C & 5 \\
E & 12 & C & E & C & E & C & E & C & E & 4 \\
F & 12 & C & C & C & E & C & E & C & E & 5 \\
G & 14 & C & C & C & E & C & C & C & E & 6 \\
H & 11 & C & C & C & E & C & C & C & C & 8 \\
I & 15 & C & E & C & C & C & E & C & E & 5 \\
J & 12 & C & E & C & C & C & E & C & E & 5 \\
K & 11 & C & C & C & C & C & C & C & C & 8 \\
L & 15 & E & C & C & C & C & C & C & E & 6 \\
M & 12 & C & E & C & C & C & E & C & E & 5 \\
N & 12 & C & C & C & C & C & C & C & C & 8
\end{tabular}

Tabela 1. Resultados do pré-teste.

\begin{tabular}{ccccccccccc}
\hline Aluno & Idade & $(1)$ & $(2)$ & $(3)$ & $(4)$ & $(5)$ & $(5)$ & $(7)$ & $(8)$ & Acertos \\
\hline A & 12 & C & E & E & E & E & E & C & E & 2 \\
B & 15 & E & X & C & C & C & C & C & C & 6 \\
C & 11 & E & C & C & C & C & X & X & C & 5 \\
D & 11 & C & X & C & E & E & C & C & X & 4 \\
E & 12 & C & C & C & C & C & C & C & C & 8 \\
F & 12 & C & C & C & C & C & C & C & C & 8 \\
G & 14 & C & C & C & C & C & C & C & C & 8 \\
H & 11 & C & C & C & C & C & C & C & C & 8 \\
I & 15 & C & C & C & C & C & X & E & C & 6 \\
J & 12 & C & C & C & C & C & X & E & X & 5 \\
K & 11 & C & C & C & C & C & X & C & C & 7 \\
L & 15 & C & C & C & C & C & X & C & C & 7 \\
M & 12 & C & E & C & C & C & E & C & E & 5 \\
N & 12 & C & C & C & C & C & C & C & C & 8
\end{tabular}

Tabela 2. Resultados do pós-teste.

\begin{tabular}{ccccc}
\hline Alunos & Idade & Pré & Pós & Diferença \\
\hline A & 12 & 3,75 & 2,5 & $-1,25$ \\
B & 15 & 7,5 & 7,5 & 0 \\
C & 11 & 10 & 6,25 & $-3,75$ \\
D & 11 & 6,25 & 5 & $-1,25$ \\
\hline Grupo Vermelho & & $\mathbf{6 , 8 7 5}$ & $\mathbf{5 , 3 1 2 5}$ & $\mathbf{- 1 , 5 6 2 5}$ \\
\hline E & 12 & 5 & 10 & 5 \\
F & 12 & 6,25 & 10 & 3,75 \\
G & 14 & 7,5 & 10 & 2,5 \\
H & 11 & 10 & 10 & 0 \\
\hline Grupo Verde & & $\mathbf{7 , 1 8 7 5}$ & $\mathbf{1 0}$ & $\mathbf{2 , 8 1 2 5}$ \\
\hline I & 15 & 6,25 & 7,5 & 1,25 \\
J & 12 & 6,25 & 6,25 & 0 \\
K & 11 & 10 & 8,75 & $-1,25$ \\
L & 15 & 7,5 & 8,75 & 1,25 \\
\hline Grupo Amarelo & & $\mathbf{7 , 5}$ & $\mathbf{7 , 8 1 2 5}$ & $\mathbf{0 , 3 1 2 5}$ \\
\hline M & 12 & 6,25 & 6,25 & 0 \\
N & 12 & 10 & 10 & 0 \\
\hline Grupo Azul & & 8,125 & 8,125 & $\mathbf{0}$ \\
\hline
\end{tabular}

Tabela 3. Notas dos alunos nos testes. 
Para comparar a diferença de conhecimento antes e depois foi atribuída uma nota a cada aluno, de 0 a 10, tendo cada questão respondida corretamente $(\mathrm{C})$ o valor de 1,25 pontos. A Tabela 3, relaciona as notas obtidas no pré-teste com as notas do pósteste, exibindo também a diferença entre as notas e as médias (do pré, pós e diferença) de cada grupo. Exibe-se a melhora de 2,8125 (28\%) do grupo verde e 0,3125 (3\%) do amarelo, bem como o mantimento da nota no grupo azul. Devido ao desinteresse do grupo vermelho, que ficaram dispersos durante a aplicação, já era previsto que fosse obter desempenho não satisfatório nos testes. Portanto, as respostas deste grupo foram classificadas como aleatórias e desconsideradas.

\section{Conclusão}

Este trabalho apresenta uma abordagem alternativa para desenvolver o PC, introduzindo métodos formais na educação básica. É disponibilizado um jogo educacional baseado em GG, do gênero estratégia, na plataforma de tabuleiro, chamado "A Última Árvore". $\mathrm{O}$ jogo explora as relações entre as GGs e o PC, das quais destacam-se: a coleta de dados através de estruturas gráficas; a análise de dados sob um formalismo com definições precisas e não-ambíguas; a abstração de sintaxes textuais substituindo-as por grafos; algoritmos e processos construídos com passos bem definidos por regras de uma GG; e o paralelismo representado de maneira natural em uma linguagem de caráter descritivo. Um dos destaques de "A Última Árvore" é sua fundamentação teórica que considera não somente os aspectos do PC e das GGs, mas também de design instrucional e de jogos. Isto revela-se importante dada a escassez de jogos educacionais desenvolvidos por meio de fundamentações e teorias bem estabelecidas em relação ao seu design relatada por Battistella (2016b). Os resultados da aplicação e avaliação notificam uma melhora no desempenho dos alunos nas competências de identificar matches, aplicar regras, lidar com atributos, coletar e analisar dados.

\section{Referências}

ANDERSON, L. W. et al. A taxonomy for learning, teaching and assessing: A revision of Bloom's taxonomy. Cognition and Instruction, v.9, n.2, p.137-175, 2001.

BARR, V.; STEPHENSON, C. Bringing computational thinking to K-12: what is Involved and what is the role of the computer science education community? Acm Inroads, New York, NY, USA, p.48-54, 2011.

BATTISTELLA, P. E.; WANGENHEIM, C. G. von. (2016a) ENgAGED: um processo de desenvolvimento de jogos para ensino em computação. thesis - Universidade Federal de Santa Catarina. Programa de Pós-Graduação em Ciência da Computação., Florianópolis, SC, BR, 2016.

BATTISTELLA, P.; WANGENHEIM, C. G. von. (2016b) Games for teaching computing in higher education-a systematic review. IEEE Technology and Engineering Education Journal, Piscataway, NJ, EUA, v.9, n.1, p.8-30, 2016.

BELL, T. et al. Computer science unplugged: School students doing real computing without computers. The New Zealand Journal of Applied Computing and Information Technology, Auckland, NZ, v.13, n.1, p.20-29, 2009.

BLOOM, B. S. et al. Taxonomy of educational objectives. Vol. 1: Cognitive domain. McKay, p.20-24, 1956.

BOMBASAR, J. et al. Ferramentas para o ensino-aprendizagem do pensamento computacional: onde está alan turing? In: SIMPÓSIO BRASILEIRO DE 
INFORMÁTICA NA EDUCAÇÃO-SBIE, 2015. Anais. . . Porto Alegre: SBC, 2015. p.81-90.

BOYLE, E. A. et al. An update to the systematic literature review of empirical evidence of the impacts and outcomes of computer games and serious games. Computers \& Education, Amsterdan, Netherlands, v.94, p.178-192, 2016.

BRANCH, R. M. Instructional design: The ADDIE approach. New York, NY, USA: Springer Science \& Business Media, 2009.

CSTA; ISTE; NSF. Computational Thinking Leadership Toolkit. Albany, NY, USA: CSTA, 2009.

EHRIG, H. Handbook of graph grammars and computing by graph transformation: volume I. Foundations. Singapore: World Scientific Publishing, 1997.

GARRIS, R. et al. Games, motivation, and learning: A research and practice model. Simulation \& gaming. v.33, n.4, p.441-467, 2002.

KIRKPATRICK, D. L.; KIRKPATRICK, J. D. Evaluating training programs: the four levels. Williston, VT, USA: Berrett-Koehler Publishers, 2006.

NAKAMURA, J.; CSIKSZENTMIHALYI, M. Flow theory and research. Handbook of positive psychology, p.195-206, 2009.

RENSINK, A. The GROOVE simulator: A tool for state space generation. In: INTERNATIONAL WORKSHOP ON APPLICATIONS OF GRAPH TRANSFORMATIONS WITH INDUSTRIAL RELEVANCE, 2003, New York, NY, USA. Anais. . 2003. p.479-485.

RESNICK, M. et al. Scratch: programming for all. Communications of the ACM, New York, NY, USA, v.52, n.11, p.60-67, 2009.

RIBEIRO, L. Métodos formais de especificação: gramáticas de grafos. VIII Escola de Informática da SBC-Sul, Porto Alegre, RS, BR, p.1-33, 2000.

SILVA JUNIOR, B. A. et al. (2017a) A Última Árvore: exercitando o Pensamento Computacional por meio de um jogo educacional baseado em Gramática de Grafos. In: BRAZILIAN SYMPOSIUM ON COMPUTERS IN EDUCATION (SIMPÓSIO BRASILEIRO DE INFORMÁTICA NA EDUCAÇÃO-SBIE), 2017. Anais. . . Porto Alegre: SBC, 2017. v.28, n.1, p.735-744.

SILVA JUNIOR, B. A. et al. (2017b) A Última Árvore: O Povo da Cidade”, utilizando a condição negativa de aplicação em um jogo educacional. In: WORKSHOP-ESCOLA DE INFORMÁTICA TEÓRICA-WEIT), 2017. Anais. . . Santa Maria: UFSM, 2017. v.4, n.1, p.144-151.

WING, J. M. Computational thinking. Communications of the ACM, New York, NY, USA, v.49, n.3, p.33-35, 2006.

WING, J. M. Computational thinking and thinking about computing. Philosophical transactions of the royal society of London A: mathematical, physical and engineering sciences, London, UK, v.366, n.1881, p.3717-3725, 2008. 